Article

\title{
Wood Protection through Plasma Powder Deposition-An Alternative Coating Process
}

\author{
Robert Köhler ${ }^{1, * \mathbb{D}}$, Philipp Sauerbier ${ }^{2}$, Gisela Ohms ${ }^{1}$, Wolfgang Viöl ${ }^{1}\left[\right.$ and Holger Militz ${ }^{2}$ \\ 1 Laboratory of Laser and Plasma Technologies, University of Applied Sciences and Arts, \\ Von-Ossietzky-Str. 99, 37085 Göttingen, Germany; gisela.ohms@hawk.de (G.O.); \\ wolfgang.vioel@hawk.de (W.V.) \\ 2 Department of Wood Biology and Wood Products, Faculty of Forest Sciences and Forest Ecology, \\ Georg-August-University of Goettingen, Büsgenweg 4, 37077 Göttingen, Germany; \\ philipp.sauerbier@forst.uni-goettingen.de (P.S.); hmilitz@gwdg.de (H.M.) \\ * Correspondence: robert.koehler@hawk.de; Tel.: +49-551-3705-212
}

Received: 12 September 2019; Accepted: 9 October 2019; Published: 11 October 2019

\begin{abstract}
In contrast to conventional coating processes such as varnishing, plasma powder deposition by means of an atmospheric pressure plasma jet on wood is not yet widely used. A key advantage of this process is that volatile organic compounds and organic solvents are avoided. In the present work, European beech (Fagus sylvatica L.) and pine sapwood (Pinus sylvestris L.) were coated with polymer (polyester), metal (aluminum coated silver) or metal oxide (bismuth oxide) particles. Furthermore, a layer system consisting of polyester and metal or metal oxide was investigated. The layer thickness and topography were analyzed with a laser scanning microscope and scanning electron microscope, revealing thicknesses of 2-22 $\mu \mathrm{m}$ depending on the coating material. In general, the chemical composition of the layers was determined using X-ray photoelectron spectroscopy and Fourier-transform infrared spectroscopy measurements. The coatings consisting of metal and metal oxide showed a band gap and plasmon resonance in the range of 540 and $450 \mathrm{~nm}$. Through this absorption, the wood may be protected against ultraviolet (UV) radiation. In the water uptake and release tests, the polyester layers exhibited a reduction of water vapor absorption after $24 \mathrm{~h}$ in $100 \%$ relative humidity $(\mathrm{RH})$ by $53 \%-66 \%$, whereas the pure metal oxide layers indicated the best desorption performance. The combination of metal oxide and polyester in the one-layer system combines the protection properties of the single coatings against water vapor and UV radiation.
\end{abstract}

Keywords: plasma powder deposition; moisture; UV protection; coating system; polyester; bismuth oxide; silver; wood protection

\section{Introduction}

Wood is a hygroscopic and porous material, which is strongly influenced by environmental conditions that change the wood properties. Two main factors are moisture and exposure to ultraviolet (UV) radiation, which influence the mechanical properties [1] and structural changes [2] in wood. In addition, a higher moisture content can promote fungal growth [3]. Therefore, it is necessary to protect the wood from environmental influences.

In order to reduce the moisture absorption of wood, three options are possible: a passive protection by structural measures, a superficial protection, e.g., by lacquers, or a deep protection by wood impregnation procedures.

In many lacquers the binders or pigments are dissolved or dispersed in organic solvents. If the solvents are based on volatile organic compounds, they are harmful to the environment [4]. An alternative could be a powder coating applied with an atmospheric pressure plasma jet (APPJ). 
In this plasma powder deposition technique, particles on a $\mathrm{nm}$ to $\mu \mathrm{m}$ scale are melted in the plasma and applied to the surface. This technique is environmentally friendly by omitting volatile organic compounds and organic solvents. Many organic and inorganic materials can be used as powder for the coating process. Another advantage of this technique is that thermally instable materials such as wood can also be coated.

Wallenhorst et al. [5,6] describe a plasma powder deposition with organic particles (PMMA) on wood. In former research it has been shown that a polyester coating could be deposited on wood and wood composites [7] but the moisture behavior has not yet been investigated. However, it is assumed that a water-repellent layer can be produced by coating with polymer particles.

As already mentioned, another problem is UV radiation. The absorption spectrum of wood, in particular lignin, shows a strong band between 200 and $400 \mathrm{~nm}$ in which the light is absorbed [8]. Due to the absorption of UV radiation, there is a radical induced depolymerization in lignin and the cellulose [9], which decomposes the wood surface. In addition to pigmented coatings and organic UV absorbers [10], protective layers based on metals or metal oxides can be used to achieve UV protection for wood.

Many semiconductors exhibit photocatalytic activity; however, this process involves the initial absorption of photons [11]. If a semiconductor with photocatalytic properties is irradiated with light of energy higher than the band gap of the semiconductor, there is a movement of electrons from the valence band to the conduction band in the semiconductor [12].

Due to the absorption, the wood could be protected from decomposition by UV light. Another possibility is the application of metal particles which show a plasmon absorption [13]. Similar to semiconductors, the particles absorb light in a certain spectral range of the light by the plasmon resonance.

For sufficient UV protection, the layers should provide an absorption range of 340-400 $\mathrm{nm}$ [14]. Widely used semiconductors with good photocatalytic properties or UV absorption are $\mathrm{ZnO}$ [15], $\mathrm{TiO}_{2}$ [16] or $\mathrm{Bi}_{2} \mathrm{O}_{3}$ [17]. Materials with plasmon absorption are silver, aluminum and gold [18]. Similar to the water-repellent coatings, metal or metal oxide layers can be applied under atmospheric conditions using the APPJ system. Atmospheric pressure plasma powder depositions were used to apply $\mathrm{ZnO}[19,20]$, copper [21,22] or aluminum layers [23] on wood.

To combine the advantages of the metal or metal oxide layers (UV-protection) and the plastic layer (moisture protection), it is evident that a combination of the layer-types is beneficial for wood protection. Such coating systems were produced using an atmospheric pressure plasma chemical vapor deposition (APCVD) process, whereby silver, copper or zinc-SiO $\mathrm{x}_{\mathrm{x}}$ coatings were produced with hexamethyldisiloxane and a metal salt solution [24,25]. One of the differences between plasma powder deposition and APCVD is the state of the matter of the starting materials to be deposited. In the APCVD, liquid precursors are used. Tshabalala and Sung [26] also describe a hybrid coating of inorganic-organic compounds produced using cold plasma chemical vapor deposition onto wood. The generated films show a lower moisture sorption of the wood samples.

In this study, metal and metal oxide, polyester and a coating system consisting of both were produced using an APPJ on European beech and pine sapwood. Bismuth oxide and aluminum silver particles were used for UV protection due to their band gap and plasmon resonance. The chemical composition of the generated layers was examined with X-ray photoelectron spectroscopy (XPS) and Fourier-transform infrared spectroscopy (FTIR) measurements. The layer thickness and topography were analyzed with laser scanning microscopy (LSM) and scanning electron microscopy (SEM). $\mathrm{UV} / \mathrm{Vis}$ spectra were recorded to determine the absorbing properties of the layer. Finally, water uptake and release tests were performed to verify the protective effect of the layers. 


\section{Materials and Methods}

\subsection{Coating Process}

The different coatings were generated using an APPJ system. The system consists of a power supply (high voltage), a self-developed spray nozzle as an electrode and a brush disperser (RBG 2000, Palas $\mathrm{GmbH}$, Karlsruhe, Germany). The plasma was generated between the high voltage electrode and the grounded spraying nozzle as an arc, which is blown out by compressed air to generate a plasma torch. The input power of the APPJ is $2 \mathrm{~kW}$, which is described by the pulsed high voltage of $15 \mathrm{kV}$ (effective voltage $2-3 \mathrm{kV}$ ) with a pulse repetition frequency of $50 \mathrm{kHz}$ and a pulse period of $5-10 \mu \mathrm{s}$. A simplified structure of the self-developed spray nozzle is shown in Köhler et al. [7].

Three general types of coatings were generated: pure polyester $(\mathrm{P})$ or metal oxide layers $(\mathrm{MOL})$ and a coating system (CS) consisting of polyester and metal oxide.

The powders used for the MOLs and CSs were bismuth oxide (Bi) (grain size $<4 \mu \mathrm{m}$ ) (bismuth (III)-oxide, Asalco GmbH, Lüneburg, Germany) and an aluminum powder coated with silver (eConduct Aluminum 203000, ECKART GmbH, Hartenstein, Germany) (eCon) (D50 = 20-26 $\mu \mathrm{m}$ ). The polyester (P) powder $(\mathrm{D} 50=45 \mu \mathrm{m})$ (Interpon 610 MZ013GF, Akzo Nobel Powder Coatings GmbH, Arnsberg, Germany) was based on iso- and terephthalic acid.

The powders were injected by compressed air via the brush disperser into the plasma jet. The particles were melted by the plasma and deposited on the tangential surface on European beech (Fagus sylvatica L.) and pine sapwood (Pinus sylvestris L.) $\left(40(\mathrm{~T}) \times 40(\mathrm{~L}) \times 10(\mathrm{R}) \mathrm{mm}^{3}\right)$, traversing in meander-shaped paths at a distance of $20 \mathrm{~mm}$ from the ground electrode. To ensure that the metal oxide was present on the surface of the CSs, the CSs were manufactured in two stages-at first, a polyester layer was sprayed onto the wood samples, afterwards the metal or metal oxide was applied. The parameters used for the coating process refer to the layers described in Köhler et al. [7,27] and are shown in Table 1 . Before the coating process, the wood samples were conditioned at $20{ }^{\circ} \mathrm{C} / 65 \%$ relative humidity $(\mathrm{RH})$ until constant mass was reached, and the densities of European beech and pine sapwood were measured with a balance (Kern KB 360-3N, KERN \& Sohn GmbH, Balingen, Germany) — the density is $690.1 \mathrm{~kg} / \mathrm{m}^{3}$ and $514.8 \mathrm{~kg} / \mathrm{m}^{3}$, respectively.

Table 1. Coating Parameters for polyester, metal oxide and metal powder.

\begin{tabular}{cccccc}
\hline Powder & $\begin{array}{c}\text { Plasma Power } \\
\mathbf{( \% )}\end{array}$ & $\begin{array}{c}\text { Process Gas Flow } \\
\text { Rate }(\mathbf{L} / \mathbf{m i n})\end{array}$ & $\begin{array}{c}\text { Substrate Scan } \\
\text { Speed }(\mathbf{m m} / \mathbf{s})\end{array}$ & $\begin{array}{c}\text { Powder Feed } \\
\text { Rate }\left(\mathbf{m}^{3} \mathbf{~} \mathbf{h}\right)\end{array}$ & $\begin{array}{c}\text { Powder Feed } \\
\text { Speed }(\mathbf{m m} / \mathbf{h})\end{array}$ \\
\hline $\begin{array}{c}\text { Polyester } \\
\text { Metal oxide/metal }\end{array}$ & 100 & 60 & 40 & 4.3 & 150 \\
\hline
\end{tabular}

After the coating process, the substrates were annealed for $8 \mathrm{~min}$ using an infrared radiation (IR) - heater (ceramic heating element (150 W), RS Components GmbH, Mörfelden-Walldorf, Germany) at a distance of $10 \mathrm{~mm}$. Afterwards, the samples were conditioned at $20{ }^{\circ} \mathrm{C} / 65 \% \mathrm{RH}$ until constant mass was reached. For the water absorption test, all surfaces except the coating surface of the sample were sealed three times with 2K-PUR boat lacquer (bacuplast Faserverbundtechnik GmbH, Remscheid, Germany). All samples were sterilized with ionizing radiation at a dose of $53.3 \mathrm{kGy}$ (Steris, Synergy Health Allershausen $\mathrm{GmbH}$, Allershausen, Germany). To determine the coating and sealing lacquer weight, the samples were compared to the untreated samples at the same conditions $\left(20{ }^{\circ} \mathrm{C} / 65 \% \mathrm{RH}\right)$.

\subsection{Surface Characterization}

The chemical surface composition was investigated u sing XPS and FTIR measurements.

The XPS data were obtained on a PHI 5000 Versa Probe II (ULVAC-PHI, Chigasaki, Japan) using monochromatic Al-K $\alpha$ radiation with a photon energy of $1486.6 \mathrm{eV}$. The detector resolution measured at the $\mathrm{Ag} 3 d_{5 / 2}$ peak was $0.6 \mathrm{eV}$ at a pass energy of $23.5 \mathrm{eV}$. Detailed spectra of carbon (C 1s), oxygen $(\mathrm{O} 1 s)$, bismuth (Bi 4f), silver (Ag 3d5) and aluminum ( $\mathrm{Al} \mathrm{2p}$ ) were recorded with a spot size of $200 \mu \mathrm{m}$, 
a pass energy of $46.95 \mathrm{eV}$ and a step size of $0.1 \mathrm{eV}$. To avoid charging effects, the measurements were carried out by neutralizing sample charging. All spectra were shifted to the main C 1 s peak at $284.8 \mathrm{eV}$.

The FTIR measurements were performed using a PerkinElmer Frontier (PerkinElmer LAS (Deutschland) $\mathrm{GmbH}$, Rodgau Jügesheim, Germany) with a diamond attenuated total reflection (ATR) (Specac Golden Gate GS 10515, Specac Ltd., Orpington, UK). The spectra were recorded at the range of $400-4000 \mathrm{~cm}^{-1}$, averaged over 64 scans and a resolution of $4 \mathrm{~cm}^{-1}$.

The UV-Vis absorbance spectra were recorded using a PerkinElmer 650 (PerkinElmer, Inc., Shelton, CT, USA) with an integrating sphere module in the range of 300-900 nm with a velocity of $10.5 \mathrm{~nm} / \mathrm{s}$ and a slit width of $5 \mathrm{~nm}$.

LSM (VK-X100, KEYENCE Deutschland GmbH, Neu-Isenburg, Germany) was used to determine the layer thickness. The measurement was conducted using a $20 \times$ objective for the polyester and CS coating and a 100x objective for the MOL. In comparison to the mean height of coated to uncoated area, the coating thickness could be determined. Before the analysis, a tilt correction was performed, and the image noise was reduced.

SEM images were performed on an EVO LS 15 (Carl Zeiss AG, Oberkochen, Germany) with an accelerating voltage of $15 \mathrm{kV}$. To avoid charging effects, the sample was pre-sputtered with a $20 \mathrm{~nm}$ gold layer.

\subsection{Water Uptake and Release Tests}

The water uptake and release tests were carried out in accordance with the procedure of Meyer et al. [28]. The uptake of liquid water, absorption and desorption of water vapor of the wood specimens were investigated after a treatment time of $24 \mathrm{~h}$. A balance with an accuracy of $0.001 \mathrm{~g}$ was used to determine all masses (Kern KB 360-3N, KERN \& Sohn GmbH, Balingen, Germany). For the water uptake and release tests, it is assumed that the coating and sealing lacquer do not absorb water.

\subsubsection{Absorption}

The samples were dried in an oven at $103^{\circ} \mathrm{C}$ to constant mass and were weighed afterwards. Then, the samples were placed in a closed plastic box on a stainless-steel perforated plate over deionized water with the coated side up. The box was stored under constant conditions of $20{ }^{\circ} \mathrm{C} / 65 \% \mathrm{RH}$. After $24 \mathrm{~h}$, the samples were weighted and the moisture content of the samples was determined using the following equation:

$$
W V A 24_{100 \% \mathrm{RH}}=\frac{\left(m_{100 \% \mathrm{RH}}-m_{0}\right)}{\left(m_{0}-m_{c}\right)} \times 100,
$$

where $W V A 24100 \% \mathrm{Rh}$ is the water vapor uptake after $24 \mathrm{~h}$ at $100 \% \mathrm{RH}, m_{100 \% \mathrm{RH}}$ the mass after $24 \mathrm{~h}$ of vapor suspended, $m_{0}$ the mass after drying at $100{ }^{\circ} \mathrm{C}$ and $m_{c}$ the mass of the coating and sealing lacquer.

\subsubsection{Desorption}

The samples were conditioned at $20{ }^{\circ} \mathrm{C} / 100 \% \mathrm{RH}$ until fiber saturation (after 28 days) and the mass was determined. Subsequently, the specimens were placed with the coated side on silica gel for $24 \mathrm{~h}$ in a closed plastic box. The box was stored under constant conditions of $20{ }^{\circ} \mathrm{C} / 65 \% \mathrm{RH}$. After $24 \mathrm{~h}$, the samples were weighted and the moisture content of the samples was determined using the following equation:

$$
W V D 24_{0 \% \mathrm{RH}}=\frac{\left(m_{F S}-m_{0 \% \mathrm{RH}}\right)}{\left(m_{F S}-m_{c}\right)} \times 100,
$$

where $W V D 240 \% \mathrm{Rh}$ is the water vapor desorption after $24 \mathrm{~h}$ at $0 \% \mathrm{RH}, m_{0 \% \mathrm{RH}}$ the mass after $24 \mathrm{~h}$ suspended on silica gel, $m_{F S}$ the mass at fiber saturation and $m_{c}$ the mass of the coating and sealing lacquer. 


\subsubsection{Liquid Water Uptake}

The specimens were dried in an oven at $103^{\circ} \mathrm{C}$ to constant mass and were weighed afterwards. The samples were submersed in deionized water in a closed plastic box. The box was stored under constant conditions of $20^{\circ} \mathrm{C} / 65 \% \mathrm{RH}$. After $24 \mathrm{~h}$, the samples were weighted and the moisture content of the samples was determined using the following equation:

$$
W 24_{\text {SUB }}=\frac{\left(m_{\text {SUB }}-m_{0}\right)}{\left(m_{\text {SUB }}-m_{C}\right)} \times 100,
$$

where $W 24_{S U B}$ is the water submersion after $24 \mathrm{~h}, m_{S U B}$ the mass after $24 \mathrm{~h}$ submersed in water, $m_{O}$ the mass after drying at $103{ }^{\circ} \mathrm{C}$ and $m_{\mathcal{C}}$ the mass of the coating and sealing lacquer.

\section{Results and Discussion}

\subsection{Average Thickness and Surface Morphology}

LSM measurements were performed to determine the average layer thickness and are shown in Figure 1. The CSs consist of polyester and bismuth oxide or polyester and eCon and are abbreviated as $\mathrm{PBi}$ and PeCon in the following. The produced layer thickness of the Bi and eCon layers is approximately $3.1 \mu \mathrm{m}$ and $4.4 \mu \mathrm{m}$, whereas the thickness of the polyester layer and the CSs is approximately $18.8 \mu \mathrm{m}$. The CSs did not show significant differences (Fischer's exact test) from the polyester coatings. Due to the constant layer thickness of the CSs and the polyester layer, it can be assumed that the metal oxide particles are embedded in the polyester coating.

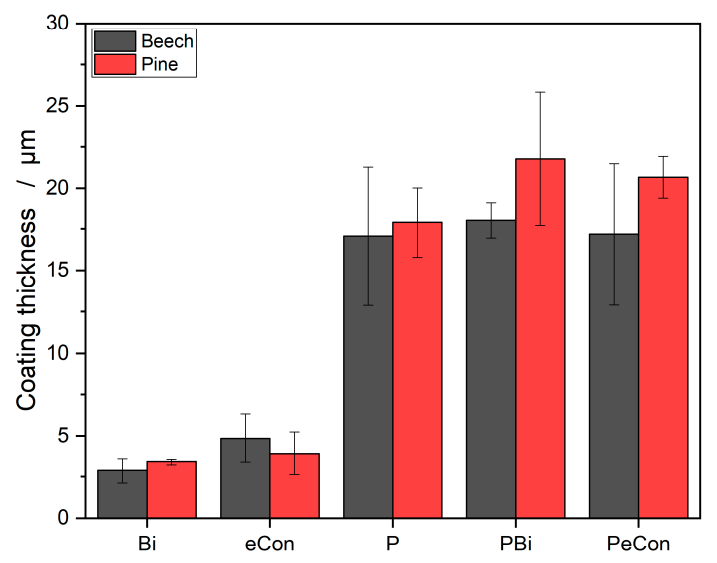

Figure 1. Coating thickness of metal oxide, polyester and coating system (CS) layer $(n=5)$.

The morphology of the coatings was assessed with SEM measurements and is shown in Figure 2. Pine and beech samples show the same layer morphology; therefore, only pine is shown here as an example. The pine reference shows the characteristic tracheides of the pine wood (a). Due to the impact on the wood surface the particles melted in the plasma form lenticular shapes which overlap each other and form a homogeneous surface. In the MOLs and the polyester coating (b)-(d) some isolated spots of the wood surface are apparent. The CSs (e) and (f) showed scattered holes on the surface. The metal oxide particles in the CSs seem to be under the surface of the polyester. In comparison to the MOLs and the CSs, the MOLs have a rather smooth surface. This could be due to the two-step coating process. In the second process step, in addition to the melting of the metal particles by the plasma, the surface of the previously deposited polyester is melted, too. It seems that by introducing the metal drops into the melt of the polyester, the metal drops are not transformed into lenticular structures but rather into spherical shapes. 

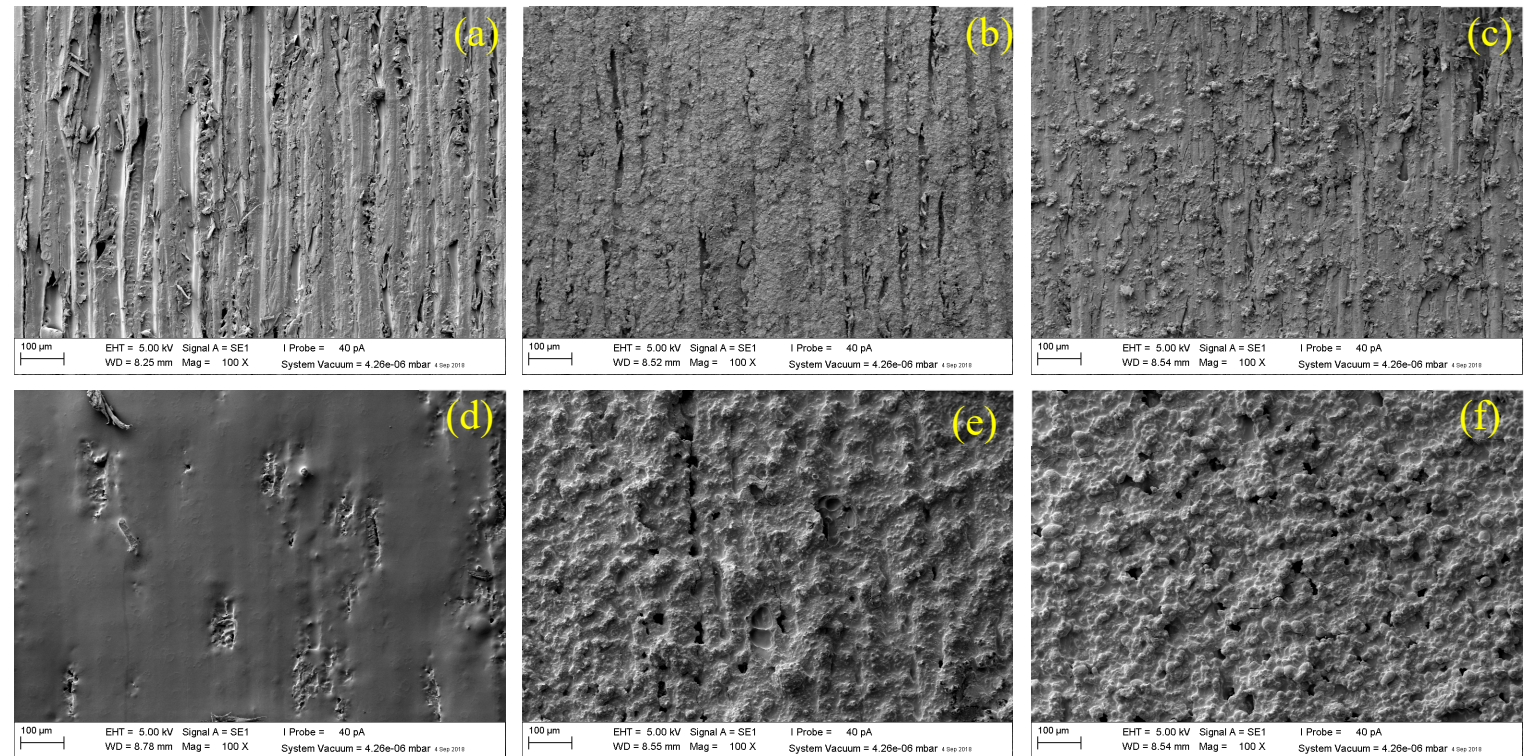

Figure 2. Scanning electron microscopy (SEM) images of pine wood (a) with different coatings: (b) Bi, (c) eCon, (d) polyester, (e) polyester and bismuth (PBi) and (f) polyester and eCon (PeCon).

\subsection{Chemical Surface Characterisation}

XPS measurements were performed in order to determine the elemental composition and binding states of the samples. Depending on the reference and the coating, different elements were detected:

- Wood reference and polyester layer: carbon (C 1s) and oxygen (O 1s),

- Bi coating and PBi: C $1 s, \mathrm{O} 1 s$ and bismuth (Bi $4 f)$

- $\quad$ eCon and PeCon: C 1s, O 1s, aluminum ( $\mathrm{Al} 2 p$ ) and silver (Ag 3d5).

A small amount of fluorine was detected in the layers with a polyester content. The atomic concentration of the samples is shown in Table 2.

Table 2. Atomic concentration of reference and coatings in atom- $\%$.

\begin{tabular}{|c|c|c|c|c|c|c|}
\hline Sample & $\mathrm{C} 1 \mathrm{~s}$ & O 1s & Al $2 p$ & $\operatorname{Ag} 3 d 5$ & Bi $4 f$ & F $1 s$ \\
\hline $\begin{array}{l}\text { Beech } \\
\text { reference }\end{array}$ & 68.14 & 31.86 & - & - & - & - \\
\hline Pine reference & 71.22 & 28.78 & - & - & - & - \\
\hline Beech P & 77.81 & 21.93 & - & - & - & 0.26 \\
\hline Pine P & 77.98 & 21.7 & - & - & - & 0.32 \\
\hline Beech Bi & 50.58 & 32.76 & - & - & 16.66 & - \\
\hline Pine Bi & 63.63 & 24.75 & - & - & 11.62 & - \\
\hline Beech PBi & 77.18 & 22.39 & - & - & 0.18 & 0.25 \\
\hline Pine PBi & 77.3 & 22.29 & - & - & 0.15 & 0.26 \\
\hline Beech eCon & 58.07 & 34.92 & 3.76 & 3.25 & - & - \\
\hline Pine eCon & 58.24 & 32.82 & 5.09 & 3.85 & - & - \\
\hline Beech PeCon & 77.13 & 22.17 & 0 & 0.21 & - & 0.49 \\
\hline Pine PeCon & 77.05 & 22.51 & 0 & 0.22 & - & 0.22 \\
\hline
\end{tabular}

In comparison to the reference of the polyester coating, the amount of carbon increased, and that of oxygen decreased by approximately $7-10$ atom- $\%$, respectively. The MOLs show a decrease of oxygen and an increase of the respective deposited metal. The chemical composition of the CSs was similar to the polyester coating with a small amount of the used metal. To confirm the assumption from the LSM and SEM measurements that the metal particles largely are embedded into the polyester, the detail spectra of carbon and oxygen were recorded, too. For a clearer presentation only the beech 
samples are shown. Figure 3 shows the $\mathrm{C} 1 \mathrm{~s}$ and O1s detail spectra of the reference, the polyester and CSs coated beech. The carbon and oxygen peek of the polyester coating have a similar structure to the CS-by the same structure and the low percentage of metal oxide at the surface it could confirm the embedding.
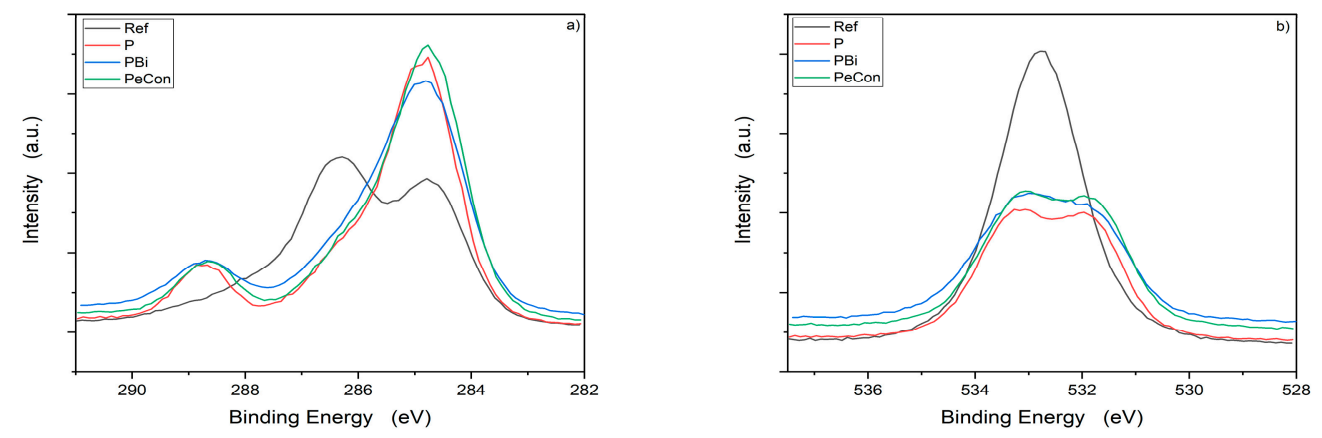

Figure 3. X-ray photoelectron spectroscopy (XPS) detail spectra of reference, polyester and CSs coated beech carbon (a) and oxygen (b).

To determine the oxidation state of the metal particle by the plasma torch, a detailed spectrum of bismuth, aluminum and silver was recorded and the peak position was analyzed. All peaks were normalized to the maximum of each spectrum. The bismuth detail spectra are shown in Figure $4 \mathrm{a}$ and consist of two peaks at the binding energies of $158.7 \mathrm{eV}$ and $164.0 \mathrm{eV}$, which correspond to the $\mathrm{Bi} 4 f_{7 / 2}$ and $\mathrm{Bi} 4 f_{5 / 2}$. The peak position indicates that bismuth (III) oxide [29,30] was applied at the surface. The peak separation of the $\mathrm{Bi} 4 f_{7 / 2}$ and $\mathrm{Bi} 4 f_{5 / 2}$ is $5.3 \mathrm{eV}$. Similarly to bismuth, the silver spectrum consists of two peaks: the $\mathrm{Ag} 3 d_{5 / 2}$ and $\mathrm{Ag} 3 d_{3 / 2}$, with a peak separation of $6 \mathrm{eV}$ (Figure $4 \mathrm{~b}$ ). The Ag $3 d_{5 / 2}$ peak for the MOLs and the CS is located at $367.9 \mathrm{eV}$ and $367.6 \mathrm{eV}$, respectively. The peak at $367.9 \mathrm{eV}$ corresponds to the $\mathrm{Ag}(0)$ oxidation state [31,32]. The peak position at $367.6 \mathrm{eV}$ is shifted to lower binding energies, which indicates the existence of silver in oxidation states [33,34]. Hsu et al. [35] explain the shift to a lower binding energy by a slight oxidation of the silver surface.
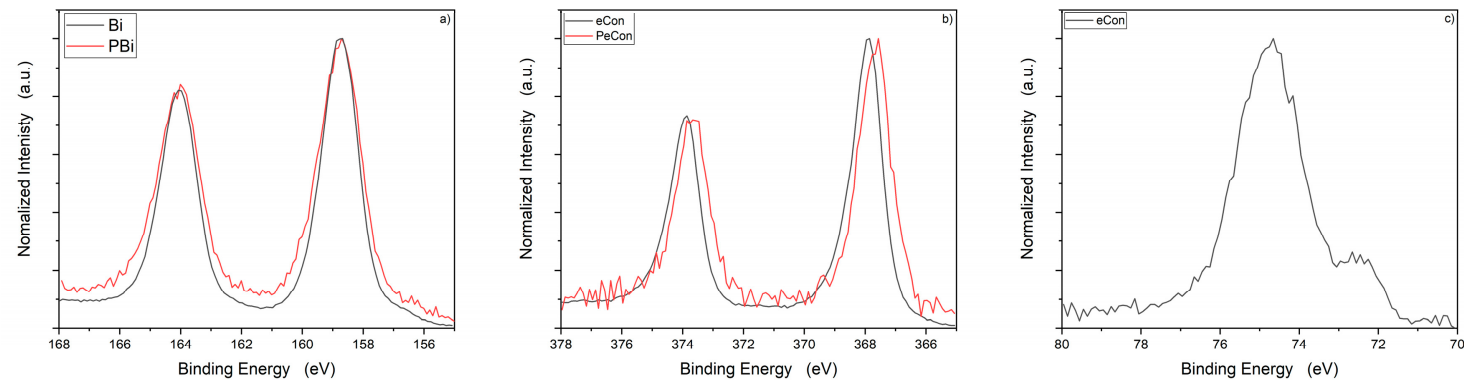

Figure 4. XPS detail spectra of (a) bismuth, (b) silver and (c) aluminum of beech coating.

Figure 4c shows the high-resolution spectra of aluminum. Only one spectrum could be shown because no aluminum was detected in the CS. The main peak at $74.7 \mathrm{eV}$ is characteristic of $\mathrm{Al}_{2} \mathrm{O}_{3}$ [36] or $\mathrm{Al}(\mathrm{OH})_{3}$ [37], whereas the small shoulder at $72.4 \mathrm{eV}$ could be identified as $\mathrm{Al}(0)$ [38].

The results of the FTIR measurements are illustrated in Figure 5a-c. Figure 5a clearly shows the broad $\mathrm{OH}$ stretch band at $3300 \mathrm{~cm}^{-1}$ for the untreated reference specimens. The peak is pronounced since the main components of wood (lignin, cellulose, hemicellulose) all contain hydroxyl groups. After coating with polyester, a new spectrum is clearly evident-the $\mathrm{OH}$ band is no longer visible, but a characteristic carbonyl peak at about $1750 \mathrm{~cm}^{-1}$ is apparent. Due to the penetration depth of the ATR-IR measurement in the $\mu \mathrm{m}$-range, a complete and area-wide coating can be assumed. 

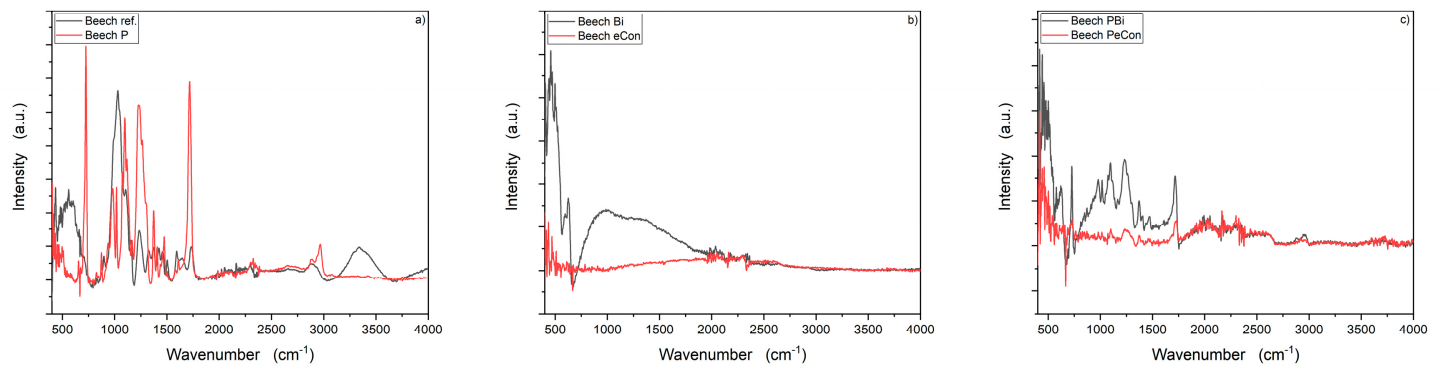

Figure 5. Coated and uncoated European beech with (a) reference and polyester coating, (b) Bi and eCon coating and (c) PBi and PeCon $(n=3)$.

Figure $5 \mathrm{~b}$ compares $\mathrm{Bi}$ and eCon coated beech FTIR spectra. The reflective characteristic of the eCon particles in IR wavelength results in a mostly peak-free spectrum for eCon. Only for bismuth MOL a characteristic peak is visible in the range of $400-700 \mathrm{~cm}^{-1}$, which is assigned to the Bi-O-Bi vibration band [39]. It should be emphasized, however, that also no peaks specific to wood are recognizable-a complete and area-wide deposited layer can again be assumed. Finally, PBi and PeCon deposits on beech are shown in Figure 5c. Again, no wood-typical peaks can be found. Characteristic polyester bands are clearly visible in case of PBi but are far less pronounced than in the pure polyester spectra shown in Figure 5a. This supports the conclusion of the XPS measurements that the metal particles are embedded. An attenuation of the characteristic polyester peaks can be explained by near-surface or not fully covering metal particles, whereby the IR radiation can indeed react with the polyester, but a significant proportion is reflected in advance by near-surface or on-surface of the metal particles.

\subsection{UV/Vis Spectroscopy}

Figure 6 shows the absorption spectra of the coatings and the wood reference measured at room temperature using UV-vis spectroscopy. The uncoated wood and the polyester coating show an absorbance in the range of 300-400 $\mathrm{nm}$ (Figure 6a). The measured spectra can be divided into two coating groups: with bismuth (Figure 6a) and with eCon (Figure 6b). All bismuth-based layers show an absorption behavior of the visible light with a wavelength $<500-550 \mathrm{~nm}$. The absorption behavior of the semiconductor allows the conclusion that bismuth oxide is present in a crystalline phase. The band gap of the crystalline semiconductor could be calculated using the Tauc plot method with the following equation [40]:

$$
(\alpha h v)^{\frac{1}{n}}=A\left(h v-E_{g}\right)
$$

where $E g, h, \alpha, v$, and $A$ are the energy of the band gap, Planck's constant, absorption coefficient, light frequency and a constant. The use of $n$ has been reported in former research [41]. The band gap energy is identified by extrapolating the straight line to the x-axis [42] in the plot $(\alpha h v)^{2}$ vs. (hv) [43] (Figure 6c). The thus determined band gap of the layers was at approximately $2.3 \mathrm{eV}$.

The eCon layers show no absorption behavior while the PeCon layers appear at a wide absorption peak at approximately $450 \mathrm{~nm}$. These peaks could be associated with the plasmon resonance (PR) of the coated silver particles [44,45]. The PR can be influenced by different material parameters like size, shape, distance [46,47], composition of the nanostructures and the dielectric properties of the surrounding environment [48]. The effect is described in the literature for nanoparticles or thin stacked metal layers $[49,50]$, which are not present in the layers produced here. A possible explanation for the PR could be that the particles were embedded close enough to each other in the polyester that PR would occur. The distance between the metal particles is sufficient for PR to occur, compared to Aslan et al. [51]. This effect cannot be observed in the eCon layers, since the particles are not embedded and no structures can be created by the impact of the particles on the wood surface, which allows PR. The PR is visible despite the slight formation of an oxide layer from the XPS results. 

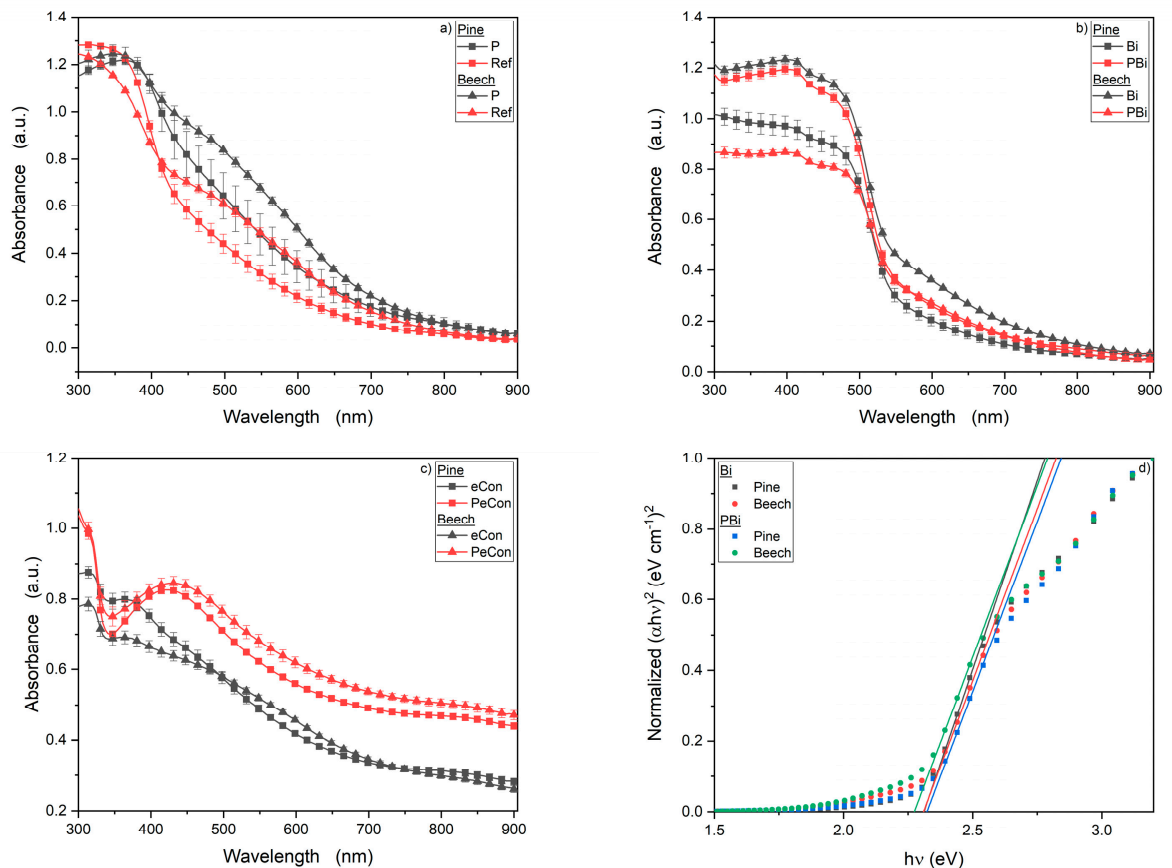

Figure 6. Absorbance spectra of coated and uncoated pine and beech wood: (a) reference and polyester coating, (b) coatings with bismuth oxide, (c) coatings with eCon (d) normalized band gap of the bismuth oxide existing layers $(n=5)$.

\subsection{Water Uptake and Release Test}

The absorption and desorption of water vapor and the absorption of liquid water were investigated in terms of the moisture behavior of the coated and uncoated wood samples. In general, the moisture content of the pine samples is higher than the beech samples. In Figure 7a, the water vapor absorption after $24 \mathrm{~h}$ is presented. In both wood species, the uncoated reference and the MOLs show the same absorption behavior, whereas the layers consisting of polyester can reduce the water vapor uptake by $53.5 \%$ and $66.0 \%$ in the beech and pine samples, respectively. The desorption is shown in Figure $7 \mathrm{~b}$. The MOLs exhibit a higher desorption than the uncoated references, while the polyester layers have the lowest desorption behavior. The CSs show the same desorption level as the uncoated wood references. The water submersion test shows no positive characteristics of the applied coatings (Figure 7c). All coated samples and the reference are at the same moisture content. The samples showed a concave form after $24 \mathrm{~h}$. The concave forms could be due to the holes in the layer surface, which were detected in the SEM images (Figure 2) as the water could only enter the sample from this side unhindered. The bend of the samples leads to the failure of the coating and partly to cracks in the front edges. This means that more water can penetrate the samples, which is reflected in the equality of the measured values. After the water submersion, the coatings were investigated with the SEM measurements (Figure 8). In the reference and the MOLs, the roughness of the surface increased after the water treatment, individual fibers are visible, and the coating acts washed out. The images of the polyester layer and the CSs reveal cracks in the surface compared to the untreated samples. 

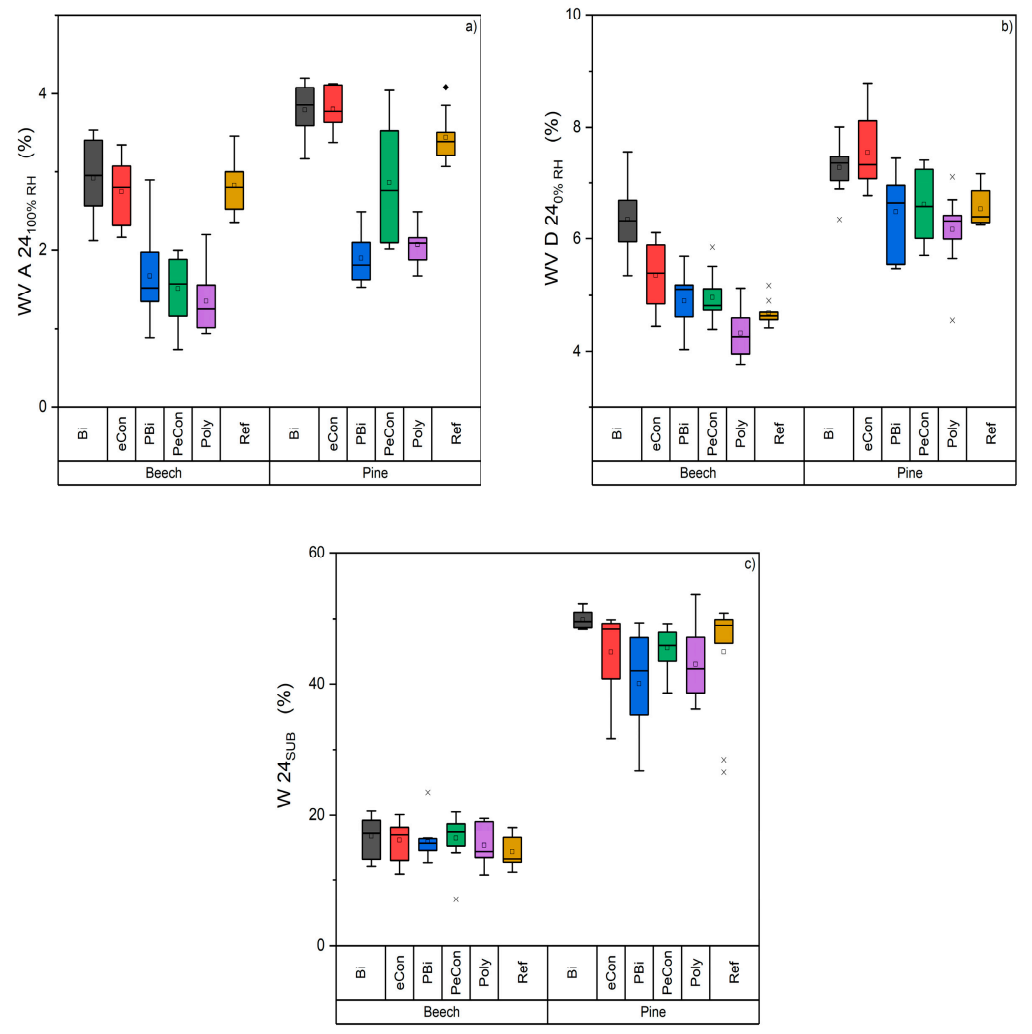

Figure 7. (a) Absorption (b) desorption of water vapor and (c) liquid water submersion of coated and uncoated beech and pine wood $(n=10)$.
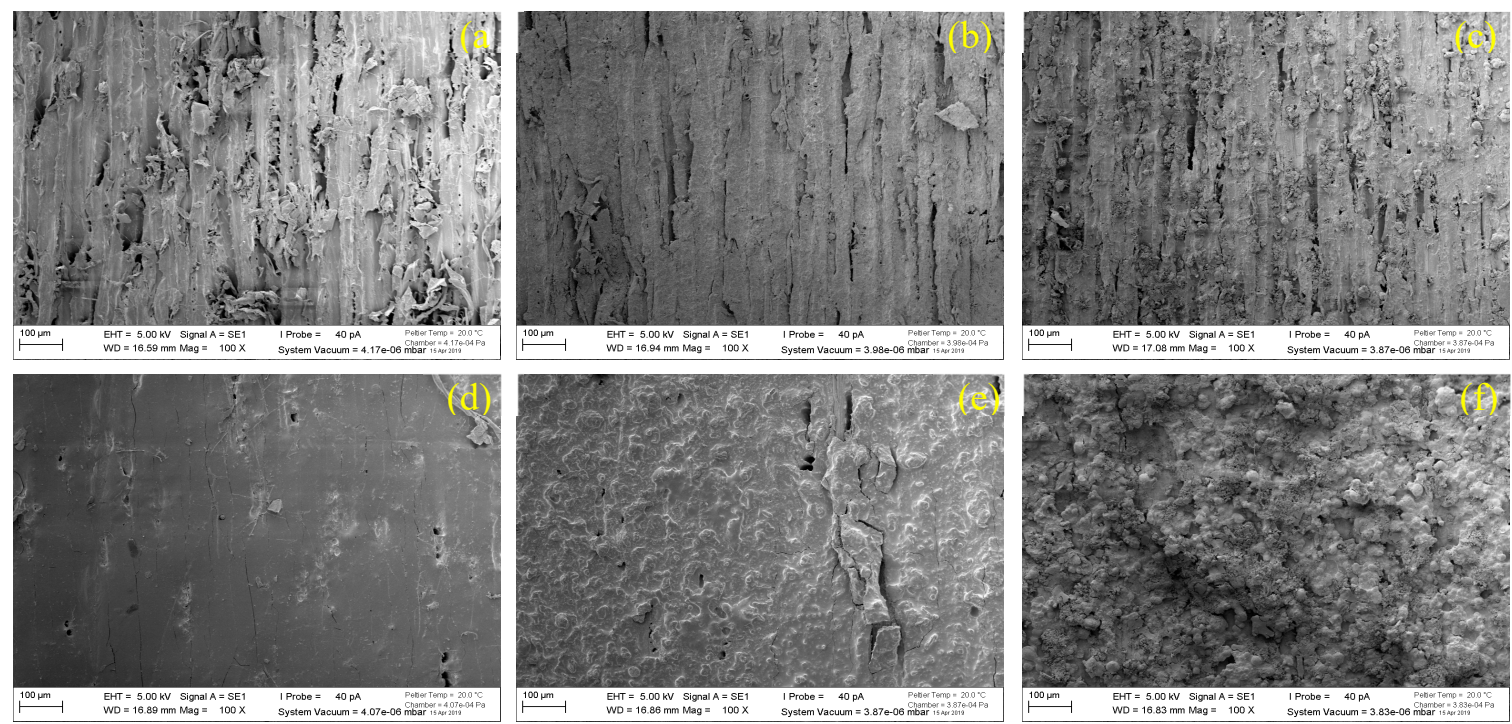

Figure 8. SEM images of pine wood (a) with different coatings: (b) Bi, (c) eCon, (d) polyester, (e) PBi and (f) PeCon after water uptake and release test.

\section{Conclusions}

In this study, three different layer types of beech- and pinewood were deposited. The results of the investigations allow the following conclusions: 
- In the CSs, the metal oxide particles are largely embedded in the polyester.

- The layers containing bismuth oxide show a band gap in the visible spectral range of light at $540 \mathrm{~nm}$, which allows its use as a potential UV protection of wood.

- The eCon MOLs show no protection against UV radiation but could reflect infrared light $(<15 \mu \mathrm{m})$.

- The CSs with eCon show plasmon resonance probably due to their structure, which also serves as UV protection for wood.

- The bismuth MOLs show good reflective properties in long-wavelength infrared.

- The polyester-containing layers show a lower absorption behavior than the metal oxide layers.

- The metal oxide layers have a higher desorption behavior than the polyester-containing layers.

- The good behavior of the layers against water vapor could not be shown in the submersion test.

- The combination of metal oxide and polyester in the one-layer system combines the positive properties of the polyester layer in absorption and the metal oxide layer in desorption. The layers created in this way protect the wood from water vapor and exhibit good desorption properties.

- The combination of metal oxide and polyester in the one-layer system combines the protection properties of the single coatings against UV radiation and water vapor.

The results discussed here indicate that plasma powder coatings offer a promising way to produce protective wood layers. In further experiments, the UV-protective properties of the generated layers will be the focus. A possible lignin degradation by UV light should be evaluated with the aid of the zero-span test. Furthermore, the parameters such as layer thickness or cover ratio should be evaluated and undergo natural weather conditions.

Author Contributions: Conceptualization, R.K.; methodology, R.K., P.S.; validation, R.K., P.S., G.O., W.V., H.M.; investigation, R.K., P.S.; resources, G.O., W.V., H.M.; writing—original draft, R.K., P.S.; writing-review and editing, R.K., P.S., G.O., W.V., H.M.

Funding: This research was funded by Bundesministerium für Bildung und Forschung (03XP0015A/B).

Acknowledgments: The authors thank the German Research Foundation (DFG) for the provision of the XPS (INST 196/8-1), Akzo Nobel Powder Coatings GmbH and ECKART GmbH for providing the used powder material. We thank Michaela Zauner and Maximilian Wentzel for the support with the SEM measurements.

Conflicts of Interest: The authors declare no conflicts of interest.

\section{References}

1. Ishimaru, Y.; Arai, K.; Mizutani, M.; Oshima, K.; Iida, I. Physical and mechanical properties of wood after moisture conditioning. J. Wood Sci. 2001, 47, 185-191. [CrossRef]

2. Weichelt, F.; Emmler, R.; Flyunt, R.; Beyer, E.; Buchmeiser, M.R.; Beyer, M. ZnO-Based UV Nanocomposites for Wood Coatings in Outdoor Applications. Macromol. Mater. Eng. 2009, 295, 130-136. [CrossRef]

3. Gezici-Koç, Ö.; Erich, S.J.F.; Huinink, H.P.; van der Ven, L.G.J.; Adan, O.C.G. Bound and free water distribution in wood during water uptake and drying as measured by 1D magnetic resonance imaging. Cellulose 2017, 24, 535-553. [CrossRef]

4. Pearnchob, N.; Bodmeier, R. Dry polymer powder coating and comparison with conventional liquid-based coatings for Eudragit@RS, ethylcellulose and shellac. Eur. J. Pharm. Biopharm. 2003, 56, 363-369. [CrossRef]

5. Wallenhorst, L.; Rerich, R.; Vovk, M.; Dahle, S.; Militz, H.; Ohms, G.; Viöl, W. Morphologic and Chemical Properties of PMMA/ATH Layers with Enhanced Abrasion Resistance Realised by Cold Plasma Spraying at Atmospheric Pressure. Adv. Condens. Matter Phys. 2018, 2018, 1-11. [CrossRef]

6. Wallenhorst, L.M.; Dahle, S.; Vovk, M.; Wurlitzer, L.; Loewenthal, L.; Mainusch, N.; Gerhard, C.; Viöl, W. Characterisation of PMMA/ATH Layers Realised by Means of Atmospheric Pressure Plasma Powder Deposition. Adv. Condens. Matter Phys. 2015, 2015, 1-12. [CrossRef]

7. Köhler, R.; Sauerbier, P.; Militz, H.; Viöl, W. Atmospheric Pressure Plasma Coating of Wood and MDF with Polyester Powder. Coatings 2017, 7, 171. [CrossRef]

8. Sakakibara, A.; Samo, Y. Chemistry of Lignin. In Wood and Cellulosic Chemistry, 2nd ed.; Hon, D.N.-S., Shiraishi, N., Eds.; Marcel Dekker: New York, NY, USA, 2001. 
9. Kiguchi, M.; Evans, P.D.; Ekstedt, J.; Williams, R.S.; Kataoka, Y. Improvement of the durability of clear coatings by grafting of UV-absorbers on to wood. Surf. Coat. Int. Part B Coat. Trans. 2001, 84, 263-270. [CrossRef]

10. Aloui, F.; Ahajji, A.; Irmouli, Y.; George, B.; Charrier, B.; Merlin, A. Inorganic UV absorbers for the photostabilisation of wood-clearcoating systems: Comparison with organic UV absorbers. Appl. Surf. Sci. 2007, 253, 3737-3745. [CrossRef]

11. Linsebigler, A.L.; Lu, G.; Yates, J.T. Photocatalysis on $\mathrm{TiO}_{2}$ Surfaces: Principles, Mechanisms, and Selected Results. Chem. Rev. 1995, 95, 735-758. [CrossRef]

12. Prakash, J.; Sun, S.; Swart, H.C.; Gupta, R.K. Noble metals- $\mathrm{TiO}_{2}$ nanocomposites: From fundamental mechanisms to photocatalysis, surface enhanced Raman scattering and antibacterial applications. Appl. Mater. Today 2018, 11, 82-135. [CrossRef]

13. Link, S.; Wang, Z.L.; El-Sayed, M.A. Alloy Formation of Gold-Silver Nanoparticles and the Dependence of the Plasmon Absorption on Their Composition. J. Phys. Chem. B 1999, 103, 3529-3533. [CrossRef]

14. George, B.; Suttie, E.; Merlin, A.; Deglise, X. Photodegradation and photostabilisation of wood-the state of the art. Polym. Degrad. Stab. 2005, 88, 268-274. [CrossRef]

15. Becheri, A.; Dürr, M.; Lo Nostro, P.; Baglioni, P. Synthesis and characterization of zinc oxide nanoparticles: Application to textiles as UV-absorbers. J. Nanopart. Res. 2008, 10, 679-689. [CrossRef]

16. Jnido, G.; Ohms, G.; Viöl, W. Deposition of $\mathrm{TiO}_{2}$ Thin Films on Wood Substrate by an Air Atmospheric Pressure Plasma Jet. Coatings 2019, 9, 441. [CrossRef]

17. Raza, W.; Haque, M.M.; Muneer, M.; Harada, T.; Matsumura, M. Synthesis, characterization and photocatalytic performance of visible light induced bismuth oxide nanoparticle. J. Alloys Compd. 2015, 648, 641-650. [CrossRef]

18. Blaber, M.G.; Arnold, M.D.; Harris, N.; Ford, M.J.; Cortie, M.B. Plasmon absorption in nanospheres: A comparison of sodium, potassium, aluminum, silver and gold. Phys. B Condens. Matter 2007, 394, 184-187. [CrossRef]

19. Wallenhorst, L.; Gurău, L.; Gellerich, A.; Militz, H.; Ohms, G.; Viöl, W. UV-blocking properties of Zn/ZnO coatings on wood deposited by cold plasma spraying at atmospheric pressure. Appl. Surf. Sci. 2018, 434, 1183-1192. [CrossRef]

20. Wallenhorst, L.M.; Loewenthal, L.; Avramidis, G.; Gerhard, C.; Militz, H.; Ohms, G.; Viöl, W. Topographic, optical and chemical properties of zinc particle coatings deposited by means of atmospheric pressure plasma. Appl. Surf. Sci. 2017, 410, 485-493. [CrossRef]

21. Gascón-Garrido, P.; Mainusch, N.; Militz, H.; Viöl, W.; Mai, C. Effects of copper-plasma deposition on weathering properties of wood surfaces. Appl. Surf. Sci. 2016, 366, 112-119. [CrossRef]

22. Nejad, M.; Shafaghi, R.; Pershin, L.; Mostaghimi, J.; Cooper, P. Thermal Spray Coating: A New Way of Protecting Wood. BioResources 2016, 12. [CrossRef]

23. Gascón-Garrido, P.; Thévenon, M.F.; Mainusch, N.; Militz, H.; Viöl, W.; Mai, C. Siloxane-treated and copper-plasma-coated wood: Resistance to the blue stain fungus Aureobasidium pullulans and the termite Reticulitermes flavipes. Int. Biodeterior. Biodegrad. 2017, 120, 84-90. [CrossRef]

24. Beier, O.; Pfuch, A.; Horn, K.; Weisser, J.; Schnabelrauch, M.; Schimanski, A. Low Temperature Deposition of Antibacterially Active Silicon Oxide Layers Containing Silver Nanoparticles, Prepared by Atmospheric Pressure Plasma Chemical Vapor Deposition. Plasma Process. Polym. 2013, 10, 77-87. [CrossRef]

25. Gerullis, S.; Pfuch, A.; Spange, S.; Kettner, F.; Plaschkies, K.; Küzün, B.; Kosmachev, P.V.; Volokitin, G.G.; Grünler, B. Thin antimicrobial silver, copper or zinc containing SiOx films on wood polymer composites (WPC) applied by atmospheric pressure plasma chemical vapour deposition (APCVD) and sol-gel technology. Eur. J. Wood Prod. 2018, 76, 229-241. [CrossRef]

26. Tshabalala, M.A.; Sung, L.-P. Wood surface modification by in-situ sol-gel deposition of hybrid inorganic-organic thin films. J. Coat. Technol. Res. 2007, 4, 483-490. [CrossRef]

27. Köhler, R.; Siebert, D.; Kochanneck, L.; Ohms, G.; Viöl, W. Bismuth Oxide Faceted Structures as a Photocatalyst Produced Using an Atmospheric Pressure Plasma Jet. Catalysts 2019, 9, 533. [CrossRef]

28. Meyer-Veltrup, L.; Brischke, C.; Alfredsen, G.; Humar, M.; Flæte, P.-O.; Isaksson, T.; Brelid, P.L.; Westin, M.; Jermer, J. The combined effect of wetting ability and durability on outdoor performance of wood: Development and verification of a new prediction approach. Wood Sci. Technol. 2017, 51, 615-637. [CrossRef] 
29. Meng, L.; Xu, W.; Zhang, Q.; Yang, T.; Shi, S. Study of nanostructural bismuth oxide films prepared by radio frequency reactive magnetron sputtering. Appl. Surf. Sci. 2019, 472, 165-171. [CrossRef]

30. Chang, B.; Liu, Q.; Chen, N.; Yang, Y. A Flower-like Bismuth Oxide as an Efficient, Durable and Selective Electrocatalyst for Artificial N 2 Fixation in Ambient Condition. ChemCatChem 2019, 11, 1884-1888. [CrossRef]

31. Kowalska, E.; Wei, Z.; Karabiyik, B.; Herissan, A.; Janczarek, M.; Endo, M.; Markowska-Szczupak, A.; Remita, H.; Ohtani, B. Silver-modified titania with enhanced photocatalytic and antimicrobial properties under UV and visible light irradiation. Catal. Today 2015, 252, 136-142. [CrossRef]

32. Maiti, N.; Thomas, S.; Debnath, A.; Kapoor, S. Raman and XPS study on the interaction of taurine with silver nanoparticles. RSC Adv. 2016, 6, 56406-56411. [CrossRef]

33. Prieto, P.; Nistor, V.; Nouneh, K.; Oyama, M.; Abd-Lefdil, M.; Díaz, R. XPS study of silver, nickel and bimetallic silver-nickel nanoparticles prepared by seed-mediated growth. Appl. Surf. Sci. 2012, 258, 8807-8813. [CrossRef]

34. Ivanova, T.; Homola, T.; Bryukvin, A.; Cameron, D. Catalytic Performance of $\mathrm{Ag}_{2} \mathrm{O}$ and $\mathrm{Ag}$ Doped $\mathrm{CeO}_{2}$ Prepared by Atomic Layer Deposition for Diesel Soot Oxidation. Coatings 2018, 8, 237. [CrossRef]

35. Hsu, K.-C.; Chen, D.-H. Microwave-assisted green synthesis of Ag/reduced graphene oxide nanocomposite as a surface-enhanced Raman scattering substrate with high uniformity. Nanoscale Res. Lett. 2014, 9, 193. [CrossRef] [PubMed]

36. Potter, D.B.; Powell, M.J.; Parkin, I.P.; Carmalt, C.J. Aluminum /gallium, indium/gallium, and aluminum /indium co-doped $\mathrm{ZnO}$ thin films deposited via aerosol assisted CVD. J. Mater. Chem. C 2018, 6, 588-597. [CrossRef]

37. Kloprogge, J.T.; Duong, L.V.; Wood, B.J.; Frost, R.L. XPS study of the major minerals in bauxite: Gibbsite, bayerite and (pseudo-)boehmite. J. Colloid Interface Sci. 2006, 296, 572-576. [CrossRef]

38. Strohmeier, B.R. An ESCA method for determining the oxide thickness on aluminum alloys. Surf. Interface Anal. 1990, 15, 51-56. [CrossRef]

39. Astuti, Y.; Fauziyah, A.; Nurhayati, S.; Wulansari, A.D.; Andianingrum, R.; Hakim, A.R.; Bhaduri, G. Synthesis of $\alpha$-Bismuth oxide using solution combustion method and its photocatalytic properties. IOP Conf. Ser. Mater. Sci. Eng. 2016, 107, 12006. [CrossRef]

40. Viezbicke, B.D.; Patel, S.; Davis, B.E.; Birnie, D.P. Evaluation of the Tauc method for optical absorption edge determination: ZnO thin films as a model system. Phys. Status Solidi B 2015, 252, 1700-1710. [CrossRef]

41. Köhler, R.; Ohms, G.; Militz, H.; Viöl, W. Atmospheric Pressure Plasma Coating of Bismuth Oxide Circular Droplets. Coatings 2018, 8, 312. [CrossRef]

42. Li, X.; Sun, Y.; Xiong, T.; Jiang, G.; Zhang, Y.; Wu, Z.; Dong, F. Activation of amorphous bismuth oxide via plasmonic Bi metal for efficient visible-light photocatalysis. J. Catal. 2017, 352, 102-112. [CrossRef]

43. Zhang, L.; Wang, W.; Yang, J.; Chen, Z.; Zhang, W.; Zhou, L.; Liu, S. Sonochemical synthesis of nanocrystallite Bi2O3 as a visible-light-driven photocatalyst. Appl. Catal. A Gen. 2006, 308, 105-110. [CrossRef]

44. Jiang, M.-M.; Chen, H.-Y.; Li, B.-H.; Liu, K.-W.; Shan, C.-X.; Shen, D.-Z. Hybrid quadrupolar resonances stimulated at short wavelengths using coupled plasmonic silver nanoparticle aggregation. J. Mater. Chem. C 2014, 2, 56-63. [CrossRef]

45. Pawar, O.; Deshpande, N.; Dagade, S.; Waghmode, S.; Nigam Joshi, P. Green synthesis of silver nanoparticles from purple acid phosphatase apoenzyme isolated from a new source Limonia acidissima. J. Exp. Nanosci. 2016, 11, 28-37. [CrossRef]

46. Klantsataya, E.; François, A.; Ebendorff-Heidepriem, H.; Sciacca, B.; Zuber, A.; Monro, T.M. Effect of surface roughness on metal enhanced fluorescence in planar substrates and optical fibers. Opt. Mater. Express 2016, 6, 2128. [CrossRef]

47. Feng, A.L.; You, M.L.; Tian, L.; Singamaneni, S.; Liu, M.; Duan, Z.; Lu, T.J.; Xu, F.; Lin, M. Distance-dependent plasmon-enhanced fluorescence of upconversion nanoparticles using polyelectrolyte multilayers as tunable spacers. Sci. Rep. 2015, 5, 7779. [CrossRef] [PubMed]

48. Li, M.; Cushing, S.K.; Wu, N. Plasmon-enhanced optical sensors: A review. Analyst 2015, 140, $386-406$. [CrossRef]

49. Rifat, A.A.; Mahdiraji, G.A.; Chow, D.M.; Shee, Y.G.; Ahmed, R.; Adikan, F.R.M. Photonic crystal fiber-based surface plasmon resonance sensor with selective analyte channels and graphene-silver deposited core. Sensors (Basel) 2015, 15, 11499-11510. [CrossRef] 
50. Jeong, S.-H.; Choi, H.; Kim, J.Y.; Lee, T.-W. Silver-Based Nanoparticles for Surface Plasmon Resonance in Organic Optoelectronics. Part. Part. Syst. Charact. 2015, 32, 164-175. [CrossRef]

51. Aslan, K.; Leonenko, Z.; Lakowicz, J.R.; Geddes, C.D. Annealed silver-island films for applications in metal-enhanced fluorescence: Interpretation in terms of radiating plasmons. J. Fluoresc. 2005, 15, 643-654. [CrossRef] 